\title{
A short review and selection of soil erosion models
}

\author{
Mara NILCA \\ University of Bucharest, Faculty of Geography \\ Mara.nilca@drd.unibuc.ro
}

\begin{abstract}
The article gives a brief review of the related literature concerning soil erosion by surface water flow and provides an outline of several currently available models. They are analyzed in terms of their model structure and spatial and temporal resolution. The focus was on selecting a number of three model approaches that potentially could be applied to the upper and middle sectors of the Prahova River Valley.
\end{abstract}

Keywords: soil erosion models, RUSLE- 3D, USPED, SPL, Prahova Valley

\section{INTRODUCTION}

Soil erosion is a widespread form of soil degradation, and it has a considerable environmental and economic impact on different scales. Even though erosion is a process shaped by natural factors, current anthropogenic interventions within the landscapes often accelerate natural erosion rates staggeringly. The determination of soil loss predisposition within a valley is considered a significant theoretical and practical issue, the knowledge of it creating premises for better risk management. Effective modeling can provide information about current erosion, its trends, and scenario analysis (Ganasri and Ramesh, 2016).

It is well known that water erosion processes occur at different intensities across the landscape. However, the spatial and temporal scales of the processes are still poorly understood, which assesses of soil erosion a complex and difficult task, with considerable uncertainties. As a consequence, there is a need to improve the understanding of erosion processes at the field, catchment and larger regional scales from the quantitative perspective, in order to be able to analyze their on-site impact on soil productivity as well as their off-site impact on streams (e.g., sedimentation and water quality)
(Wickenkamp et al., 2000; Romero and Stroosnijder, 2002).

Localization of erosion-prone areas and quantitative estimation of soil loss rates with sufficient accuracy is of great significance in creating premises for better risk management and implementing appropriate erosion control and soil conservation practices (Shi et al., 2004). Equally, erosion research is important to enhance understanding of landform development across temporal and spatial scales (Slattery et al., 2002; Wainwright et al., 2003).

Although over the last 20 years there has been impressive progress in the development of mathematical tools for erosion modeling, several important issues remain unsolved, as follows (Saavedra, 2005):

(i) Many current methods require a large number of experimental input data which is unavailable.

(ii) The need to integrate model algorithms that consider all the effects of terrain shape.

(iii) The need to integrate model algorithms across distinctive spatial and temporal scales.

(iv) The need to validate both spatial and quantitative aspects of model predictions.

(v) The continued need for experimental research for deriving soil and land cover input parameters for process-based erosion models. 


\section{SIGNIFICANCE OF SOIL EROSION FOR THE STUDY AREA}

The upper and the middle sectors of the Prahova River Valley is an important socio-economic region that contains infrastructure connecting the southern and northern regions of Romania. This area is heavily affected by slope and river processes related to the growing demand of an expanding population leading to an intensification of house building and road construction.

Generally, there is a good qualitative understanding of the main causes of soil erosion at the local level. Nonetheless, research is required to get more of the quantitative information needed for predicting potential soil erosion in order to design and select the proper management solutions. While soil erosion rates based on field measurements are not available at the catchment or regional scale, they may be monitored at a plot or field scale. Even so, such data is often not comparable because of non-standardized methodologies and, non-uniform experimental conditions.

\section{SPATIAL SCALE AND SCALING}

The scale has great importance in soil erosion modeling and policy making because it influences model development and selection, as well as data availability and quality.

Models perform at certain scales, but not necessarily those matching the process or observation scales. Scaling is an adjustment in either spatial or temporal scale and has a certain direction and magnitude (Bogena and Diekkrüger, 2002). It evaluates modifications in the characteristics of an object or process when its scale is changed proportionally. The gathered data used in such studies can be generalized or simplified based on dominant properties and processes, and on the spatial and temporal variability at the scale of interest. The process, if simplifying complex geomorphologic phenomena into distinct units, is often referred to as regionalization (Bernert et al., 1997). Hence landscapes are spatially heterogeneous areas; each regionalization method has to be developed in such a manner that it fulfills the requirement for a specific scale (Turner, 1989).

One of the major challenges in soil erosion modeling, when applying the concept of scaling, is to identify how topographical attributes change if the spatial resolution of the digital model (DEM) is modified. (Zhang et al., 2002). Vigiak (2005), Xia, and Clarke (1997) report that a common concern is that the parameters build on a scale or several different scales are input into a model that operates on another scale. Although it is difficult to scale a complex ensemble of parameters and models to corresponding process scales, it is feasible to identify several scalable parameters within the complex erosion processes to improve the model accuracy (Pecknold et al., 1997).

\section{TEMPORAL AND SPATIAL VARIABILITY}

Simple empirical erosion models estimate relatively steady, long-term erosion based on statistical analysis from long-term observation. Factually, erosion rates are highly dynamic and challenging to capture due to the limited resolution of the input data and complex, multiscale interaction. More sophisticated models can perform continuous time simulations of several interacting processes that incorporate steady-state impacts of rainfall events over several years. However, they require types and scales of data that usually are unavailable.

Soil erosion can be dominated by a few extreme events. However, low magnitude, high-frequency events can also have a significant contribution to long-term erosion rates. Frequency distributions constructed from time series of measured erosion events are usually highly skewed, which has a significant impact on the simple arithmetic mean for the sample (Baffaut et al., 1998; Boardman and Favis-Mortlock, 1999). It must be noted that in some cases, a more statistically suitable measure of central tendency is the median value.

Spatial variability in landscape-scale, soilerosion processes require discretization of landscape representation in georeferenced spatial information. These necessities have led to the coupling of modeled hydrological and erosion processes to GIS. GIS-based erosion models are used for simulating sediment and water transport at hillslope, watershed, or landscape scales, and predicting erosional risk. Simple erosion models have limited capacities to identify the precise location of sediment sources and sinks, and the patterns of their propagation. 


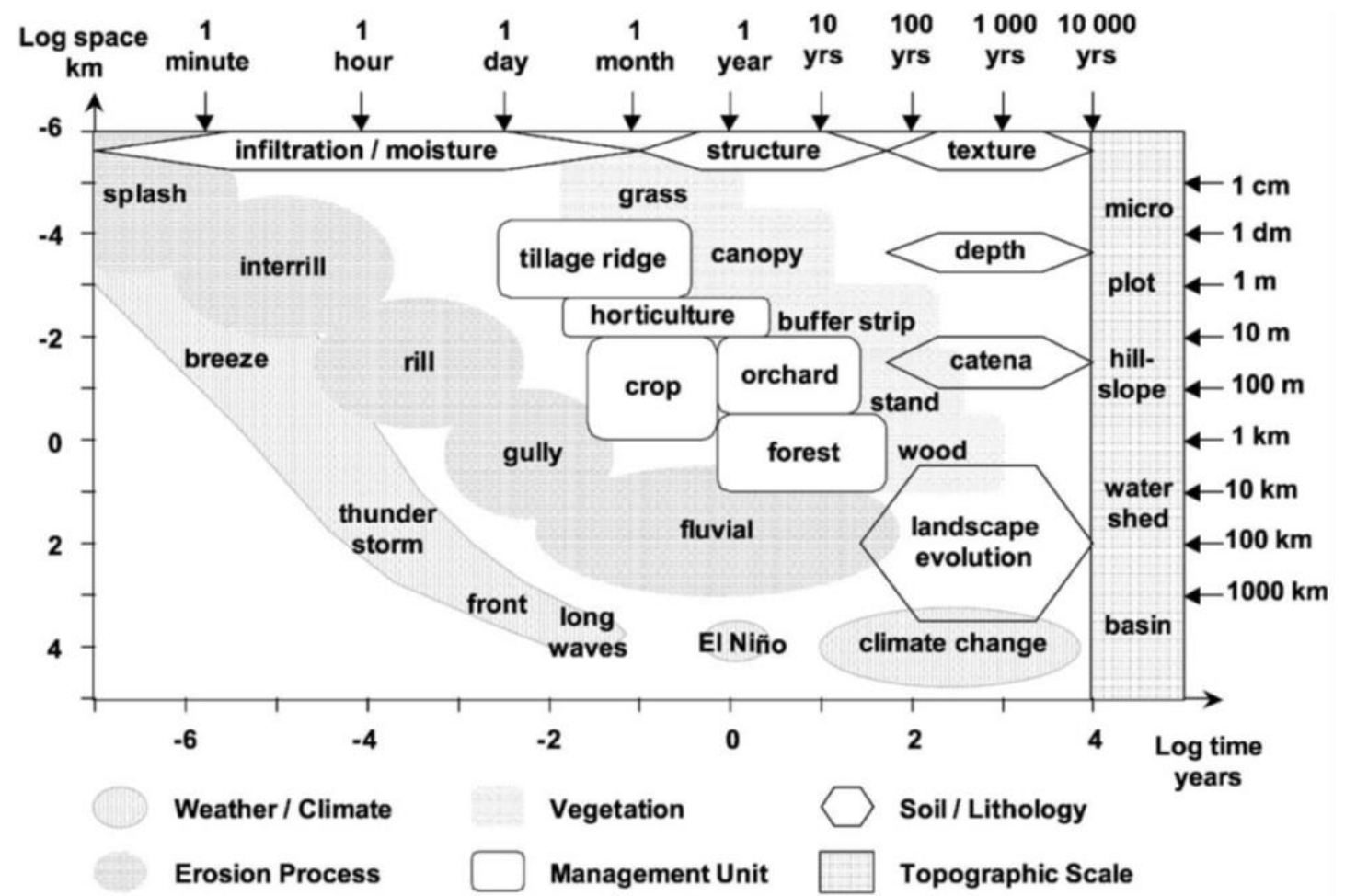

Fig. 1 Time and space extent of atmospheric, topographic, soil, and vegetation phenomenon important for dominant soil erosion processes. The management units indicate the extent of human interest and impact. (after Renschler and Harbor, 2002)

Shorter time scales are usually correlated with smaller spatial scales because finer time resolution requires more detailed modeling of the erosion process (Bull and Kirkby, 1997). At different scales, different groups of processes are dominant, and therefore the objective of the model changes with the spatial and temporal variation (Fig. 1).

\section{A SHORT REVIEW OF SOIL EROSION MODELS}

A wide range of soil erosion models has been developed in the past few decades, each differing in terms of physical processes simulated by the model, the model algorithms describing the processes, and the data dependence of the model (Bull and Kirkby, 1997).

The model complexity is determined by the details of the processes simulated, which can be translated not only in a great number of equations but also in the high number of input parameters (Merritt et al., 2007). Several factors should be taken into consideration when choosing the model: (i) dataset requirements of the model; (ii) fundamental assumptions of the model; (iii) model capabilities and susceptibilities; (iv) the components of the model; (v) user-friendliness of the model; (vi) the objectives of the model; (vii) the scales of the model outputs; (viii) hardware and software requirements of the model (Hajigholizadeh et al., 2018).

Soil erosion models are divided into three main categories: empirical or statistical, conceptual, and physical-based models. They can also be described as a hybrid between the 2 of those classes.

\subsection{Empirical models}

Empirical models are convenient as a first step in identifying soil erosion sources due to the limited data and parameter input. The most famous examples of empirical models include the Universal Soil Loss Equation (USLE) and its derivates RUSLE (Revised Universal Soil Loss Equation), as well as MUSLE (Modified Universal Soil Loss Equation). According to Smith (1999), empirical models are incredibly useful in many situations, given that they are, to no small extent, the only models that could run with little available data. In his opinion, their main limitations are: (a) are based 
on statistical analysis and yield only approximate and probable outcome; (ii) are not practical for the prediction of soil loss on an event basis; (iii) estimate soil erosion on a single slope; (iv) does not represent the process of sedimentation; (v) are restricted to the sheet, and rill erosion; and (vi) soil losses and gains over neighboring areas are not considered. However, another limitation is its applicability to areas with different ecological conditions other than from which the data were used in their development. While criticisms are valid these limitations restrict the use of more complex models. Such models are generally based on the assumption of stationarity. This assumption limits the potential of empirical models to be eventresponsive and to predict the effects of catchment change (Saavedra, 2005).

\subsection{Conceptual models}

Placed between empirical and physically based models, conceptual models aim by reflecting the physical processes governing the system by describing them with empirical relationships, e.g., Agricultural Non-Point Source (AGNPS) (Tesfahunegn, 2011). Conceptual models indicate the qualitative and quantitative effects of land-use changes, without requiring large amounts of input data (Merrritt et al. 2003). Factors such as rainfall and runoff for input and, sediment yield as output are used. These models have the inherent disadvantages of the empirical models and require relatively detailed data for calibration.

\subsection{Physically based}

Physically-based models are implemented in more complex situations, using mathematical equations dealing with the laws of conservation of energy and mass (Morgan, 2005) to provide an understanding of the fundamental sediment producing process and have the capability to access the spatial and temporal variations. Those models are generally the most accurate and flexible in input and output and are based on a comprehension of the physical processes that cause erosion.

Therefore, they apply to a wide range of ecological conditions (Lilly et al., 2009). Similarly, Ganasri and Ramesh (2016) agreed that physically based models are data-intensive, and the amount of data needed is not readily available and often challenging to parametrize.

Many different erosion and sediment -nutrient transport models are currently available. These models differ in complexity, the processes modeled, the scale to which they are applied, and assumptions on which they are based.

\section{MODEL SELECTION}

The reasonableness of the model and the availability of the data are the leading principles when selecting a model. In practice, the environmental data that are obtainable contain information to describe, only the dominant process active in a given system, which may be described effectively by conceptual processes (Young, 1998). Indeed conceptual models (semi- empirical) offer a compromise between the need to explicitly deal with the main physical processes and the limited data availability, and may, therefore, be appropriate in characterizing the distribution of erosion within the catchment (i.e., Van Rompaey et al. (2003a) and Vigiak et al. (2005) obtained acceptable results with a simple transport-limited erosion model whose main driving factor was topography).

For the present study tree distributed conceptual models (RUSLE - 3D, Revised Universal Soil Loss Equation-3D; USPED, Unit Stream Power - based Erosion Deposition; SPL, Stream Power Law) were selected based on a set of criteria of : (i) relatively low data demands, (ii) ease of use, (iii) easier parameter estimation, (iv) GIS integration and (v) potential for improvements (Table 1). The selected models allow the prediction of the location of erosion source and/or depositional areas, as well as the quantity of soil. They predict erosion rates on an annual basis, considering the spatial distribution of the hydrological and erosional model variables. 
Table 1. Main characteristics of the selected models

\begin{tabular}{|c|c|c|c|}
\hline Model & $R U S L E-3 D$ & USPED & $S P L$ \\
\hline Temporal scale & $\begin{array}{l}\text { - Event } \\
\text { - Annual }\end{array}$ & $\begin{array}{l}\text { - Event } \\
\text { - Annual }\end{array}$ & $\begin{array}{l}\text { - Event } \\
\text { - Annual }\end{array}$ \\
\hline $\begin{array}{l}\text { Climatic data } \\
\text { requirements }\end{array}$ & $\begin{array}{l}\text { - R-factor } \\
\text { - Event } \mathrm{EI}_{30}\end{array}$ & $\begin{array}{l}\text { - R-factor } \\
\text { - Event } \mathrm{EI}_{30}\end{array}$ & $\begin{array}{c}\text { - Annual rainfall } \\
\text { amount }\end{array}$ \\
\hline $\begin{array}{l}\text { Hydrological data } \\
\text { requirements }\end{array}$ & $\begin{array}{c}\text { - Rainfall } \\
\text { - Upslope } \\
\text { - Contributing area }\end{array}$ & $\begin{array}{l}\text {-Runoff amount } \\
\text { - Peak flow }\end{array}$ & - Runoff amount \\
\hline $\begin{array}{l}\text { Main drivers for soil } \\
\text { erosion }\end{array}$ & $\begin{array}{c}\text { - Rainfall erosivity } \\
\text { - Slope }\end{array}$ & - Unit stream power & - Stream power \\
\hline $\begin{array}{c}\text { Catchment } \\
\text { representation }\end{array}$ & - Raster based & - Raster based & - Raster based \\
\hline
\end{tabular}

\section{REFERENCES}

Baffaut, C., Nearing, M.A., Govers, G. (1998). Statistical distribution of soil loss from runoff plots and WEPP model simulations. Soil Sci. Soc. Am. J. 62, 756-763.

Bernert, J.A., Eilers, J.M., Sullivan, T.J., Freemark, K.E., Ribic, C. (1997). A quantitative method for delineating regions: an example for the western corn belt plains ecoregion of the USA. Environ. Manage. 21 (3), 405- 420.

Boardman, J., Favis-Mortlock, D. (1999). Frequency magnitude distributions for soil erosion, runoff and rainfall-a comparative analyses. Z. Geomorphol., Suppl. 115, 51-70.

Bogena, H.R. and Diekkrüger, B. (2002). Modelling solute and sediment transport at different spatial and temporal scales. Earth Surface Processes and Landforms, 27(13): 1475-1489.

Bull, L.J., Kirkby, M.J. (1997). Gully processes and modelling. Progress in Physical Geography 21 (3), 354-374.

Ganasri, B.P., and Ramesh, H. (2016). Assessment of Soil Erosion by RUSLE Model Using Remote Sensing and GIS - A Case Study of Nethravathi Basin. Geoscience Frontiers, 7:953-961.

Hajigholizadeh, Mohammad \& Melesse, Assefa \& Fuentes, Hector (2018). Erosion and Sediment Transport Modelling in Shallow Waters: A Review on Approaches, Models and Applications. International Journal of Environmental Research and Public Health. 15. 518. 10.3390.

Lilly, A., Grieve I.C., Jordan C., Baggaley N.J., Birnie R.V., Futter M.N., Higgins A., Hough R., Jones M.,
Nolan A.J., Stutter M.I., Towers W. (2009). Climate change, land management and erosion in the organic and organo-mineral soils in Scotland and Northern Ireland. Scottish Natural Heritage Commissioned Report No. 325 (ROAME No. F06AC104 -SNIFFER UKCC21.

Merrritt, W.S., Letcher, R.A., and Jakeman, A.J. (2003). A Review of Erosion and Sediment Transport Model. Environmental Modelling and Software, 18:761-799.

Morgan, R.P.C., (2005). Soil Erosion and Oonservation. Third edition. Blackwell Publishing, Malden, U.S.A.

Romero, C.C. and Stroosnijder, L. (2002). A multiscale approach for erosion impact assessment for ecoregional research in the Andes., Proceedings SAAD-III, Lima, Peru.

Saavedra, C. P. (2005). Estimating spatial patterns of soil erosion and deposition in the Andean region using geo - information techniques : a case study in Cochabamba, Bolivia. Enschede: International Institute for Geo-Information Science and Earth Observation.

Shi, Z.H., Cai, S.F., Ding, S.W., Wang, T.W. and Chow, T.L. (2004). Soil conservation planning at the smallwatershed level using RUSLE with GIS: a case study in the Three Gorge area of China. Catena, 55: 33-48.

Slattery, M., Gares, P.A. and Phillips, D. (2002). Slopechannel linkage and sediment delivery on North Carolina coastal plain cropland. Earth Surface Processes and Landforms, 27: 1377-1387.

Smith, H.J. (1999). Application of Empirical Soil Loss Models in Southern Africa: A Review. South African Journal of Plant and Soil, 16(3):158-163. 
Tesfahunegn, G.B. (2011). Soil Erosion Modelling and Soil Quality Evaluation for Catchment Management Strategies in Northern Ethiopia. Ph.D. Thesis, Rheinischen Friedrich-Wihelms University

Turner, M.G. (1989). Landscape ecology: the effect of pattern on process. Annu. Rev. Ecol. Syst. 20, 171-197.

Van Rompaey, A.J.J., Krasa, J., Dostal, T. and Govers, G. (2003b). Modelling sediment supply to rivers and reservoirs in Eastern Europe during and after collectivization period. Hydrobiologia, 494: 169-176.

Vigiak, O., Okoba, B.O., Sterk, G. and Groenenberg, S. (2005). Modelling catchment-scale erosion patterns in the East African Highlands. Earth Surface Processes and Landforms, 30(2): 183-196.

Wainwright, J., Parsons, A.J., Michaelides, K., Powell, D.M. and Brazier, R. (Editors) (2003). Linking short and long term soil erosion modelling. In: Long Term Hillslope and Fluvial System Modelling. Concepts and Case Studies from the Rhine River Catchment. Springer-Verlag, Bonn, Germany

Wickenkamp, V., Duttmann, R. and Mosimann, T. (2000). A multiscale approach to predicting soil erosion on cropland using empirical and physically based soil erosion models in a geographic information system. In: J. Schmidt (Editor), Soil Erosion: Application of $\mathrm{PhD}$.

Xia, A. and Clarke, K.C. (1997). Approaches to scaling of geo-spatial data. In: D.A. Quattrochi and M.F. Goodchild (Editors), Scale in Remote Sensing and GIS. CRC Lewis, Boca Raton, Florida, USA, pp. 309-360.

Young, PC. (1998). Data-based mechanistic modelling of environmental, ecological, economic and engineering systems. Environmental \& Software. 13:105-122.

Zhang, X. (2002). Scaling issues in environmental modelling, Environmental Modelling: Finding simplicity in complexity. John Wiley \& Sons Ltd. 